\title{
Práticas Pedagógicas Inovadoras, uma Abordagem Centrada em EAC - Experiência de Aprendizagem Combinada: o Caso de uma Instituição de Ensino Superior do Noroeste Gaúcho
}

\section{Innovative Pedagogical Practices, an EAC - Centered Approach - Combined Learning Experience: the Case of a Higher Education Institution in Northwest Gaúcho}

Nedisson Luis Gessi ${ }^{1 *}$, José Romeu Marconcine, Gabriele Schek, Carine Eloise Zimermann, Juliane Colpo, Flávia Michelle Pereira Albuquerque, Camila Gabriele Câmara, Denise Felber Chaves

\begin{abstract}
RESUMO
O mundo em transformação vem demandando de todos aqueles que se dedicam à educação repensar tempos, espaços e relações no ambiente educativo. No caso do Ensino Superior e da formação profissional, essas mudanças são condição para a reinvenção da forma com que concebemos a educação. Desse modo, o tema do presente estudo está alinhado com as Práticas Pedagógicas Inovadoras com uma abordagem do EAC - Experiência de Aprendizagem Combinada, tendo como objetivo verificar como a EAC integrada com as metodologias ativas impacta na melhoria dos resultados no processo de ensino-aprendizagem no Ensino Superior. O presente estudo assume uma perspectiva metodológica alicerçada na pesquisa exploratória, descritiva e aplicada. Em relação aos procedimentos técnicos utilizados, destaca-se a pesquisa bibliográfica e estudo de caso, quanto ao método de abordagem optou-se pelo hipotético-dedutivo. Quanto ao marco teórico, buscou-se evidenciar os temas relacionados a Metodologias Ativas de aprendizagem, as novas tecnologias nos contextos educacionais, práticas pedagógicas inovadoras e o novo perfil docente. Constatou-se que o uso de metodologias ativas combinada com as TICs - Tecnologias da Informação e da Comunicação e plataformas de aprendizagem, engajam mais os estudantes no processo de aprendizagem e gera melhores resultados, encurtando a distância entre a teoria e prática combinada com a utilização de casos reais. Concluiu-se que investir na formação continuada dos docentes é alicerce de sustentação da proposta do EAC, bem como investir em novas tecnologias e plataformas adaptáveis e cada vez mais personalizáveis as demandas dos estudantes e do mercado.
\end{abstract}

Palavras-chave: Práticas Pedagógicas; Aprendizagem; Metodologias Ativas; Perfil Docente; Inovação no Ensino Superior.

\section{ABSTRACT}

The changing world has been demanding that all those who are dedicated to education rethink times, spaces and relationships in educational spaces. In the case of higher education and professional training, these changes are a condition for reinventing the way we conceive education. Thus, the theme of this study is aligned with the Innovative Pedagogical Practices with an approach of the EAC (Combined Learning Experience) aiming to verify how the EAC integrated with active methodologies impacts on the improvement of results in the teaching-learning process in the University education. The present study assumes a methodological perspective based on exploratory, descriptive and applied research, in relation

\footnotetext{
${ }^{1}$ Faculdades Integradas Machado de Assis.

*E-mail: nedisson@fema.com.br
} 
to the technical procedures used, the bibliographical research and the case study stand out. As for the theoretical framework, we sought to highlight themes related to Active Learning Methodologies, new technologies in educational contexts, innovative pedagogical practices and the new teacher profile. It was found that the use of active methodologies combined with ICTs - Information and Communication Technologies and learning platforms more engages students in the learning process and generates better results by shortening the distance between theory and practice combined with the use of real cases. It was concluded that investing in the continuing education of teachers is the foundation for sustaining the EAC proposal, as well as investing in new technologies and platforms that are adaptable and increasingly customizable to the demands of students and the market.

Keywords: Pedagogical Practices; Learning; Active Methodologies; Teacher Profile; Innovation in Higher Education.

\section{INTRODUÇÃO}

A nova realidade mundial vem pleiteando uma reestruturação dos ambientes educativos, a fim de atender as demandas das transformações do mundo do trabalho e seus impactos na sociedade. Neste novo contexto, o modelo de pedagogia alicerçado na divisão entre pensamento e ação, na memorização e divisão de conteúdos abriu espaço para a inovação pedagógica por meio de novas experiências educativas em que o livro didático deixou de ser o principal responsável pela qualidade do trabalho educativo. Ampliaram-se os espaços de aprendizagem para além da sala de aula e do próprio ambiente escolar, demandando uma transformação estrutural que não depende exclusivamente do acesso às TICs, mas que pode ser viabilizada e potencializada pela inclusão de novas tecnologias.

No caso do Ensino Superior e da formação profissional, este movimento de superação dos moldes tradicionais de ensino são condição para a reinvenção da forma com que concebemos a educação tanto nos espaços formais quanto não formais, bem como no crescente mundo da educação a distância e híbrida.

No entanto, não basta levar conexão às escolas e fornecer equipamentos para alunos e professores. Essas ações só são consolidadas e produzem resultados positivos expressivos quando associadas a práticas pedagógicas voltadas a inovação nos ambientes educativos.

Dito isto, tem-se como principal característica da chamada reinvenção da educação, a mudança no papel dos professores, que deixam de ser os detentores do conhecimento e passam a mediar o processo de aprendizagem, que tem os estudantes como "agentes" e "autores" do conhecimento. 
Este movimento pedagógico se denomina "metodologias ativas de aprendizagem", por colocar o estudante no centro do processo de aprendizagem e com um papel ativo na construção de conhecimentos, em vez de deixá-los ocupar um papel passivo nas salas de aula tradicionais, enfileirados e olhando para a frente, aguardando a transmissão de conhecimento de seus professores (BACICH; MORAN, 2018). Portanto, a educação é diretamente afetada por este novo contexto, ampliando a equidade no acesso aos estudos e avançando de maneira surpreendente na qualidade do aprendizado.

A base epistemológica para essa revolução ora em curso, que vem abalando o modelo tradicional das escolas e universidades, está assentada no construtivismo e no trabalho de autores como John Dewey, Jean Piaget, Lev Vygostsky, Seymour Papert e o brasileiro Paulo Freire. Todos eles são precursores dos movimentos atuais que buscam ressignificar a educação.

As metodologias ativas não são uma prática nova, muito menos uma novidade teórica, a mesma está alicerçada na defesa de uma educação interativa e dialógica, pressupondo uma corresponsabilidade do estudante por seu processo de aprendizagem de forma a contrapor a chamada "Educação Bancária", em que os professores simplesmente transmitem informações para serem depositadas nas mentes de seus estudantes e memorizadas.

Mas curiosamente, metodologias ativas estão na moda hoje. Passaram nas últimas décadas e particularmente nos últimos anos, a serem objetos de estudo e pesquisa, sendo também debatidas em eventos acadêmicos, congressos e mesmo na imprensa, vindo naturalmente a fazer parte de cursos de formação de professores.

Esse movimento, de certa forma, contribui para repensar e fundamentar melhor a prática docente e a necessidade de novos espaços de aprendizagem que contemplem o estudante como centro do processo de aprendizagem e o professor como peça chave nesse processo, passando a ser um mediador, uma espécie de mentor que conduz o estudante na jornada do aprendizado. Para isso, o professor terá que se apropriar das novas tecnologias da informação e comunicação, as chamadas TICs. E não obstante, as Instituições de Ensino devem acompanhar as novas tendências e buscar constantemente qualificar o corpo docente e também encorajar os professores a fazer uso das novas tecnologias nos contextos educacionais, principalmente no ensino superior.

O modo como está estruturado tanto a escola como a universidade nos dias atuais, evidencia um modelo de educação que existe há mais de um século, modelo esse que 
contribui para a disseminação do conhecimento e também visa reduzir as desigualdades através da ascensão social proporcionada pelo saber. No entanto, este mesmo modelo se mostra atualmente incapaz de sustentar os novos desafios da sociedade contemporânea.

O atual modelo parte da premissa que a realidade prática se dá a partir da aplicação direta da teoria, por isso aplica boa parte do seu tempo transmitindo informações teóricas, na expectativa que o estudante seja capaz de dar aplicabilidade a ela quando necessário. Mas de fato, não é isto que ocorre. Quando o estudante se depara com a prática (geralmente tardiamente), se vê totalmente despreparado para enfrentá-la.

Desse modo, o tema de estudo do presente trabalho está alicerçado nas Práticas Pedagógicas Inovadoras com ênfase na abordagem da EAC em uma IES - Instituição de Ensino Superior, localizada na região Noroeste do Estado do Rio Grande do Sul.

O foco paradigmático do atual modelo está no que o professor ensina e não no que o estudante aprende. Se o professor fosse avaliado pelo que o estudante aprendeu e não pelo que ele ensinou, a realidade educacional seria muito melhor. A base do atual modelo é "ouvir-entender-memorizar-repetir-exercitar". A estrutura curricular é fragmentada em disciplinas e pressupõe que, de algum modo, o estudante seja capaz de realizar a integração destes elementos. Soma-se a essa realidade a falta de preparo e formação do professor para ser um educador. Ele é um profissional de determinada especialidade que procura transmitir o que sabe de algum modo empírico, do mesmo modo que seus professores fizeram com ele.

Não obstante a isso, confunde-se ensino com aula. As DCNs - Diretrizes Curriculares Nacionais, preconizam a formação de um egresso com perfil generalista, humanista, crítico e reflexivo. Estas competências propostas são impossíveis de serem desenvolvidas somente por meio de aulas expositivas. Nos dias de hoje, a evolução dos meios de comunicação e informação mudaram a forma como vemos e nos comunicamos, promovendo impactos diretos na sociedade, educação, cultura, economia, relações pessoais, etc. No entanto, há 30 anos os educadores prestavam pouca atenção ao trabalho dos cientistas cognitivos e os pesquisadores do campo das ciências cognitivas trabalhavam distantes da realidade das salas de aula. Hoje o que percebemos é uma aproximação maior dos pesquisadores cognitivos com os ambientes educacionais, dedicando maior tempo aos processos de gestão da aprendizagem por parte dos professores, testando e refinando suas teorias em salas de aulas reais. 
Nesse contexto, tem-se como problemática de estudo: Como a EAC, integrada com as metodologias ativas, pode contribuir para a melhoria dos resultados no processo de ensino-aprendizagem no Ensino Superior?

Ainda que as formas tradicionais de ensino sejam importantes, elas não podem ser o foco exclusivo dos esforços para melhorar o desempenho na aprendizagem. A busca do saber também precisa se concentrar nas transformações sociais e econômicas, na realidade do ambiente de trabalho e em refletir experiências para se aprender a partir do que já aconteceu.

Assim, torna-se necessário pensar novos modelos para novos tempos, modelos preocupados em facilitar a aprendizagem, minimizar o excesso de aulas expositivas que segundo estudos demostraram baixo impacto de aprendizagem, mudar o foco do aluno de sujeito passivo para um sujeito autônomo e capaz de aprender a aprender. Assim, percebese a necessidade de mudanças para atender os novos desafios da contemporaneidade, em especial na passagem da ênfase no conteúdo e no conhecimento conceitual (declarativo) para o destaque nas competências e no conhecimento estratégico. Mudanças de foco na metodologia expositiva de ensino para metodologias ativas de aprendizagem, ou simplesmente mudança do foco no ensino para o foco na aprendizagem.

Portanto, o objetivo do presente estudo é verificar como a EAC integrada com as metodologias ativas impacta na melhoria dos resultados no processo de ensinoaprendizagem no Ensino Superior.

Diante dos desafios atuais interpostos à educação de distintos níveis, modalidades e contextos, torna-se necessário o repensar do fazer docente e as metodologias utilizadas, pois as possiblidades de desenvolvimento da prática pedagógica por meio de metodologias ativas combinadas com recursos digitais (TICs) e plataformas de aprendizagem no ensino presencial, se colocam como um diferencial no processo ensinoaprendizagem (BACICH; MORAN, 2018).

Assim sendo, o presente trabalho justifica-se face a necessidade de implantar/implementar no contexto das práticas pedagógicas inovadoras, o uso das tecnologias digitais emergentes combinada com plataformas de aprendizagem e metodologias ativas, no intuído de colaborar para uma aprendizagem mais significativa, visando aproximar a teoria da prática no dia a dia dos estudantes, seja na vida pessoal ou nos contextos organizacionais dos quais os mesmos estejam inseridos. 


\section{REFERENCIAL TEÓRICO}

Para realização deste estudo, foram abordados temas como: Metodologias Ativas de aprendizagem, as novas tecnologias nos contextos educacionais, práticas pedagógicas inovadoras e o novo perfil docente.

\section{METODOLOGIAS ATIVAS DE APRENDIZAGEM}

Metodologias ativas de aprendizagem são mecanismos didáticos que colocam o estudante direta e ativamente no centro do processo de aquisição do conhecimento, pois concentram o ensino e a aprendizagem no "fazer para aprofundar o saber". Por vezes, tais metodologias caracterizam-se pelo envolvimento de todos os participantes de um determinado grupo, ou seja, professores e estudantes se envolvem na busca, localização e utilização de informações relevantes que possam promover responsabilidade individual e coletiva (NEVES; MERCANTI; LIMA, 2018).

Cabe ressaltar que o sucesso do ensino e da aprendizagem por meio das metodologias ativas só se faz com o pleno engajamento de professores e estudantes nas atividades propostas. Os métodos utilizados devem contemplar os diversos estilos de aprendizagem presentes dentro da sala de aula.

Assim, as discussões colocadas pelas "metodologias ativas" têm como ponto de partida o fomento e a obtenção da autonomia dos estudantes e como agentes do próprio processo de aprendizagem, de maneira que sejam corresponsáveis pela aquisição de conhecimento, o qual deixa de ser obtido por mera transmissão de um emissor e passa a ser construído a partir de sua maior intervenção ou engajamento durante as atividades desenvolvidas ao longo da jornada acadêmica (BACICH; MORAN, 2018).

Os benefícios resultantes do uso das metodologias ativas são potencializados em relação à metodologia tradicional de ensino, focada praticamente no monólogo do professor dentro da sala de aula. As metodologias ativas aprofundam os conhecimentos, estimulam a comunicação, ampliam a capacidade de ouvir a outra pessoa falar, estimulam as atividades coletivas e colaborativas, desenvolvem a motivação individual e coletiva, bem como diversificam os estilos individuais de aprendizagem. A Ilustração a seguir apresenta a comparação entre as características de estilos de aprendizagem dos diferentes milênios, conforme Mattar (2010): 
Ilustração 1 - Estilos de aprendizagem - novo milênio e milênio anterior

\begin{tabular}{|l|l|}
\hline Estilos de aprendizagem do novo milênio & Estilos de aprendizagem do milênio anterior \\
\hline $\begin{array}{l}\text { Fluência em múltiplas mídias; valoriza cada uma } \\
\text { em função dos tipos de comunicação, atividades, } \\
\text { experiências e expressões que ela estimula. }\end{array}$ & $\begin{array}{l}\text { Centra-se no trabalho como uma mídia única, } \\
\text { mas adequada ao estilo e às preferências do } \\
\text { indivíduo. }\end{array}$ \\
\hline $\begin{array}{l}\text { Aprendizado baseado em experiências de pesquisa, } \\
\text { peneira e sintese coletiva, em vez da localização e } \\
\text { absorção de informações em alguma fonte } \\
\text { individual melhor; prefere aprendizado comunal } \\
\text { em experiências diversificadas, tácitas e situadas; } \\
\text { valoriza o conhecimento distribuido por umal de fontes de informação } \\
\text { comunidade e em um contexto, assim como o } \\
\text { conhecimento de um indivíduo. }\end{array}$ & \\
\hline $\begin{array}{l}\text { Aprendizado ativo baseado na experiência (real e } \\
\text { simulada) que inclui oportunidades frequentes para } \\
\text { reflexão (por exemplo, infundindo experiências na } \\
\text { simulação Virtual University, em um curso sobre } \\
\text { liderança em universidade); valoriza estruturas de } \\
\text { referência bicêntricas (em que é possível enxergar } \\
\text { os objetos por dentro e por fora) e imersivas que } \\
\text { infundam orientação e reflexão no aprendizado } \\
\text { pelo fazer. }\end{array}$ & \\
\hline $\begin{array}{l}\text { Expressão por meio de teias não lineares e em fases distintas. } \\
\text { associativas de representações em vez de histórias } \\
\text { lineares (por exemplo, criar uma simulação em uma } \\
\text { página Web para expressar a compreensão em vez } \\
\text { de escrever um artigo); usa representações } \\
\text { envolvendo simulações ricamente associadas e } \\
\text { situadas. }\end{array}$ & \\
\hline $\begin{array}{l}\text { Codesign de experiências de aprendizado } \\
\text { personalizadas para necessidades e preferências } \\
\text { individuais. }\end{array}$ & $\begin{array}{l}\text { Enfatiza a seleção de uma variante } \\
\text { precustomizada de uma gama de serviços } \\
\text { oferecidos. }\end{array}$ \\
\hline
\end{tabular}

Fonte: MATTAR (2010)

Ainda, segundo Moran (2015) as metodologias ativas se apresentam como pontos de partida para o avanço dos processos mais elevados de reflexão, de integração cognitiva, de generalização e reelaboração de novas práticas. Percebe-se que o estímulo ou fomento à autonomia do estudante é importante para que ele integre a cadeia formativa do conhecimento, que é o mote das metodologias ativas de aprendizagem, discussão não totalmente nova, mas que tem se tornado uma das principais pautas do ensino superior nos últimos anos (MORAN, 2015).

No contexto do ensino superior, o assunto tem ganhado projeção em razão da constatação, na maioria das vezes, do não engajamento crítico dos estudantes e do pouco comprometimento em termos formativos, dando continuidade a uma realidade deficitária prévia, inclusive. Soma-se a isso, o insuficiente e quase inexistente contato com 
abordagens mais trans e interdisciplinares durante o curso superior, reduzindo as possibilidades de o estudante ter melhores condições de se diferenciar no mercado de trabalho quando se tornar egresso (ZABALA, 1998; FAZENDA, 2008).

Percebe-se a necessidade de promover a aprendizagem significativa, pois é fundamental o envolvimento do estudante onde ele se coloca como protagonista do processo e lhe dê capacidade de desenvolver o senso crítico, permitindo aquisição de competências que associem seus conhecimentos às transformações do mundo real. Isso parece ser possível usando metodologias ativas de aprendizagem, que são ferramentas, caminhos, estratégias que permitem elevar o estudante a ser o protagonista de sua própria formação profissional, pavimentando o conhecimento através da mediação e acompanhamento do professor (VASCONCELLOS, 2011).

Nesse sentido, é papel das Instituições de Ensino Superior criar mecanismos para que os estudantes sejam criativos e inovadores, levando-os a ter disposição, interesse e imaginação. Mais do que garantir-lhes saber, é preciso garantir que saibam aplicar o aprendido nas mais diversas situações (FAZENDA, 2008).

Atualmente, as práticas tradicionais têm sido muito questionadas, pois permitem ao estudante pouca participação. Na mesma velocidade em que as informações circulam, é necessário utilizar práticas pedagógicas inovadoras, motivadoras. Acredita-se hoje que o estudante da contemporaneidade deva ser capaz, diante de tantas competências exigidas, auto gerenciar seu processo de formação. Logo, as metodologias ativas despertam o estudante e o fazem sair do seu estado passivo de expectador, permitindo o desenvolvimento de habilidades e competências de forma significativa a partir da construção do próprio conhecimento (NEVES; MERCANTI; LIMA, 2018).

\section{AS NOVAS TECNOLOGIAS NOS CONTEXTOS EDUCACIONAIS}

O uso de Tecnologias de Informação e Comunicação (TICs) pode gerar intermediações culturais, ideias, emoções, atitudes e habilidades, propiciando uma relação cognitiva e interativa do aluno com o objeto do conhecimento.

Segundo Lucena (1997),

A tecnologia fundamenta um novo estilo educacional em busca de um novo paradigma, através do qual, o aluno tem possibilidades de desenvolver suas estruturas lógicas, seu raciocínio crítico e sua 
capacidade de decisão, preparando-se para uma nova sociedade, onde a manipulação da informação é o eixo principal. (LUCENA, 1997, p.14)

Empregar a tecnologia para transformar ou melhorar a educação é um processo natural. Os computadores e a Internet introduzidos na escola exigem, mesmo que mínima, posse de capital cultural. As escolas vivem um momento em que a disseminação das tecnologias, mais especificamente do computador no processo educativo, tem sido o catalisador de uma mudança no paradigma educacional.

Fagundes discorre que, em ambientes de aprendizagem informatizados, com microcomputadores ligados em redes local e internacional (Internet), novas dimensões de interação são acrescentadas (FAGUNDES, 1997).

Com o emprego das TICs como ferramentas educacionais, o aluno resolve problemas significativos. Isso pode ocorrer, por exemplo, através do uso de aplicativos como editores de textos e apresentações, planilhas eletrônicas, jogos interativos e outros aplicativos correlatos que favoreçam a aprendizagem ativa, isto é, que propicie o desenvolvimento do aluno a partir de suas próprias ações. Nessa abordagem o computador não é o detentor do conhecimento, mas um facilitador de sua construção, sendo utilizado como ferramenta que permite ao aluno o desenvolvimento cognitivo.

É importante destacar que o computador é apenas ferramenta e não substitui o professor. Demo acrescenta que, para que o uso das TICs se torne motivo de aprendizagem, é imprescindível a presença de um professor que saiba unir duas habilidades essenciais: saber alfabetizar e saber lidar com a máquina. Assim, pode-se construir o melhor ambiente possível de alfabetização, em especial usando as simulações virtuais (DEMO, 2007).

A educação também contribui à determinação do modo pelo qual as pessoas usam as tecnologias e os benefícios que os estudantes obtêm deste uso, ou seja, "a informática e a internet podem ou não transformar o aprendizado e o ensino: a sua mera existência não criará pesquisadores ou buscadores de conhecimento entre as pessoas sem base ou habilidades necessárias" (WARSCHAUER, 2006, p.152).

Quando a educação é reforçada por meio da tecnologia, os resultados podem ser muito diferentes. Warschauer (2006) afirma que,

$\mathrm{Na}$ educação reforçada por computador, um currículo mais amplo já está estabelecido, baseado em cursos e conteúdo de áreas como matemática, ciência, estudos sociais e mestria em relação à língua. $\mathrm{O}$ 
desafio aqui não é criar um currículo inteiramente novo, mas utilizar a tecnologia para reforçar as finalidades educacionais mais amplas. (WARSCHAUER, 2006, p. 177)

No processo de troca das diferentes formas de ler, dizer, fazer, compreender, aprender e ensinar que circulam entre os alunos e professores, é que o aprendizado vai se constituindo.

A informática possibilitou o surgimento de inúmeros softwares e aplicativos desenvolvidos especialmente para a educação na construção do conhecimento. $O$ ambiente de uma sala de aula informatizada é um ambiente novo, onde experiências que tenham um significado educativo emergem como uma nova concepção do processo ensino-aprendizagem, uma vez que com a informação instantânea carregada de imagens e sons de aplicativos multimídia, o aluno consegue contextualizar conceitos nunca antes imaginados em sala de aula, motivando-o ao prazer de aprender.

Nesse sentido, é importante compreender a importância de implantar/implementar práticas pedagógicas inovadoras e a necessidade de investimentos em formação continuada dos docentes, alinhada ao contexto de um novo perfil docente conectado com as demandas do século XXI.

\section{PRÁTICAS PEDAGÓGICAS INOVADORAS E O NOVO PERFIL DOCENTE.}

Um dos maiores problemas enfrentados por instituições de ensino hoje é o medo e a capacidade dos professores em inovar. A utilização das TICs são poderosos aliados no processo de transformação para metodologias e técnicas que focam nas formas de aprendizagem dos alunos.

É preciso buscar modelos e formas de ensinar com o uso das tecnologias. "Se o professor ensinar com o apoio das TICs, os seus alunos, futuros professores, vão provavelmente seguir o seu exemplo, num fenômeno de modelação de comportamento." (CAVALHEIRI ET AL., 2013, p. 134).

O processo de inovação falha no momento em que o professor se convence de que os resultados que obtém do processo ensino e aprendizado são bons com os mesmos métodos que ele vem usando repetidamente por um longo período. Para Cavalheiri et al. (2013), 
Podemos dizer que a opção pela utilização de ambientes enriquecidos em tecnologia é perfeitamente justificada, tanto mais que desta forma estamos a aproximar a escola da sociedade, local onde afinal os alunos estão inseridos e terão de sobreviver, seja na sua vida pessoal, seja na sua vida profissional. (CAVALHEIRI ET AL., 2013, p. 137).

A mudança para o uso das TICs em sala de aula busca acrescentar valor ao processo educativo. Esse processo deve ser acompanhado por alterações de caráter pedagógico e institucional, uma vez que "uma escola envolvida em ambientes tecnologicamente enriquecidos tem de possuir um padrão de comportamento capaz de otimizar os seus recursos e fazer uma demonstração sistemática do bom uso das tecnologias.” (CAVALHEIRI ET AL., 2013, p. 140). Dessa forma, a TIC será envolvida nos processos de trabalho de forma natural.

Segundo Cavalheiri et al., no processo de adoção das tecnologias em sala de aula é preciso ter sempre em mente seus destinatários principais: alunos e professores. "A tecnologia funciona desde que os seus utilizadores se sintam confortáveis no seu uso. Se ao mesmo tempo que se equipam as escolas, se proporcionar formação em contexto aos docentes, estamos certos que a utilização das TICs será substancialmente incrementada nos espaços de sala de aula”. (CAVALHEIRI ET AL., 2013, p. 141).

No tocante aos vários aspectos das práticas pedagógicas inovadoras contemporâneas, vê-se como objeto de análise o professor, sendo ele um dos pontos chaves na condução das práticas pedagógicas inovadoras, com papel relevante em tempos de grandes transformações no contexto educacional do século XXI.

Será que o professor está preparado para um cenário de constantes mudanças, impactadas principalmente pelo acelerado desenvolvimento das tecnologias da informação e comunicação, que por sua vez, vem transformando a maneira como nos comunicamos, nos relacionamos e aprendemos?

Em um mundo cada vez mais inteligente, a utilização de recursos de inteligência artificial nos mais diversos campos do conhecimento, inclusive na educação, tem avançado a passos largos, conforme o relatório Intelligence Unleashed, elaborado pelo grupo britânico Pearson (FAVA, 2019).

No mundo inteiro, cada vez mais escolas e universidades lançam mão das máquinas inteligentes para aprimorar o ensino e o aprendizado. Sendo assim, são necessários professores mais versáteis: "versatilidade tem relação com a capacidade de ampliar o conhecimento em situações diferentes" (Fava, 2018), neste mundo em rápida 
metamorfose, cada vez mais os professores deverão ser capazes de se adaptar, crescer e aprender constantemente: "quem ensina aprende ao ensinar e quem aprende ensina ao aprender" (Freire, 1997).

Da mesma forma que os nossos estudantes devem estar preparados para uma educação do futuro, onde não basta apenas ter conhecimento, é preciso saber aplicá-los. Aos professores a recíproca é a mesma, ou seja, não basta ter o conhecimento se não souber potencializá-lo e poder abstrair o melhor de cada estudante, propondo modelos inovadores e repensando sua prática em sala de aula.

Portanto, para que possam ser desenvolvidas habilidades nos estudantes, tanto de profundidade (pensamento analítico e resolução de problemas), quanto de amplitude (raciocínio indutivo, dedutivo, síntese, trabalho em equipe e criatividade), são imprescindíveis professores preparados para atender a tamanho desafio. Os professores cada vez mais terão que voltar "aos bancos escolares", utilizando aqui uma metáfora para elucidar a necessidade de o professor estar constantemente se aperfeiçoando e atento as inovações que surgem no mundo educacional. Segundo Carmo (2018), é preciso buscar novas estratégias pedagógicas para garantir um aprendizado mais interativo, instigante e ligado com as situações reais do dia a dia, e o professor é peça chave nesse processo.

Para o sucesso completo, as instituições educacionais também precisam ser versáteis, investir constantemente na formação continuada de seus professores, em infraestrutura e ambientes adequados para tornar possível o desenvolvimento de práticas de forma inovadora. Nesse contexto, todos ganham: os estudantes, os professores, a instituição e a comunidade de forma geral.

A mudança do foco no ensino para o foco na aprendizagem requer uma ruptura do paradigma educacional atual, onde o ensino através da transmissão de conteúdos com ênfase conceitual preso em estruturas disciplinares, cede espaço para um modelo de aprendizagem que valoriza o manejo estratégico do conhecimento, ou seja, um modelo que permita ao estudante aprender a ter o conhecimento de como produzir conhecimento e conhecer e aplicar procedimentos sobre como, quando e onde utilizar o conhecimento, ou seja, ênfase na aplicabilidade.

Dessa forma, o novo modelo teria o professor como um mediador do processo de instrução, onde esse mediador seria capaz de criar um ambiente propício para a aprendizagem, gerando um conjunto de problemas dentro dos quais o estudante (agora sujeito ativo do processo) busque informações e a transforme em conhecimento que possa 
ser aplicado para resolução dos problemas gerados, com vistas a busca de respostas criativas, inovadoras e originais para solução de tais problemas.

Os novos modelos são desafiadores, podemos destacar alguns elementos que constituem o modelo com foco na aprendizagem: Aprendizagem centrada no estudante protagonismo do estudante; Aulas estruturadas por meio dos objetivos de aprendizagem; O professor como mediador, motivador e desafiador; Espaço para aprender a aprender; Estímulo a criatividade, a inovação, a solução de problemas e a contextualização com a realidade do estudante; Ampliação da interatividade; Foco na aplicabilidade; Uso de estratégias como metodologias ativas, entre outras; Currículos integrados em que as competências vão sendo trabalhadas ao longo do processo de aprendizagem, focada na solução de problemas reais.

Em síntese, há muitos especialistas em educação que defendem a tese de que os atuais contextos educacionais que conhecemos hoje, sejam substituídos por "espaços de aprendizagem" bastante diversificados. Além da tecnologia, o professor é peça chave para o sucesso desses espaços. Assim, o perfil desse profissional requer novas habilidades, dentre as quais o professor passa a ajudar o estudante a transformar a informação em conhecimento e sua aplicabilidade, na busca de soluções criativas e inovadoras para os problemas demandados pela sociedade contemporânea.

Na sequencia foi apresentada a metodologia que esta organizada em três tópicos: categorização da pesquisa, geração de dados e análise e interpretação dos dados.

\section{CATEGORIZAÇÃO DA PESQUISA}

Quanto a sua natureza, o presente estudo enquadra-se como uma pesquisa teórica e aplicada, pois necessita de um embasamento teórico e pesquisas de diferentes autores, que dão embasamento ao estudo em questão e posteriormente essas bases teóricas são aplicadas na prática, dessa forma é também uma pesquisa aplicada.

Em relação ao tratamento dos dados, a pesquisa é conceituada como mista, sendo quantitativa, uma vez que explica os conteúdos através de dados brutos e diretos, obtidos por meio de questionários/entrevista com os coordenadores dos cursos superiores e diretores da IES, com o intuito de coletar os dados empíricos que serão analisados. Também é considerada como uma pesquisa qualitativa, pois busca compreender as preferências, o comportamento e as experiências individuais do público entrevistado. 
Gil afirma que “[...] em relação aos objetivos mais gerais, ou propósitos, as pesquisas podem ser classificadas em exploratórias, descritivas e explicativas." (GIL, 2010, p.27). Portanto, os fins da presente pesquisa são exploratória, descritiva e explicativa. É exploratória por se tratar de estudos bibliográficos e um estudo de caso feito através de entrevistas com coordenadores dos cursos superiores e os diretores da IES. É caracterizada como descritiva, pois possui a coleta de dados por meio de questionários semiestruturados. E, por fim, é explicativa porque além de explorar e descrever os dados, a pesquisa busca entender as causas e os efeitos que esses dados apresentam.

Ainda em relação aos dados primários da pesquisa, pode-se considerar como bibliográfica, documental e estudo de caso, visto que, é bibliográfica por se basear em materiais anteriormente publicados por autores diversos; documental uma vez que será revisado os documentos que evidenciam as práticas pedagógicas inovadoras na IES; e um estudo de caso por estudar uma aplicação prática do dia a dia que busca analisar os resultados obtidos com as práticas pedagógicas inovadoras na IES objeto do presente trabalho.

\section{GERAÇÃO DE DADOS}

Quanto a geração dos dados, os mesmos serão obtidos através da aplicação de um questionário/entrevista, que se caracteriza como documentação direta com observação direta extensiva. Segundo Lakatos e Marconi "A documentação direta constitui-se, em geral, no levantamento de dados no próprio local onde os fenômenos ocorrem. Esses dados podem ser obtidos de duas maneiras: através de pesquisa de campo ou [...] de laboratório.” (LAKATOS; MARCONI, 2010, p.169).

A coleta ou geração dos dados é o momento em que se define a forma como as informações essenciais para a pesquisa serão coletadas. Neste caso foi aplicada a documentação indireta, através de pesquisas bibliográficas e documental, buscando compreender os conceitos e aplicação das Metodologias Ativas de aprendizagem, gamificação nos espaços de aprendizagem, as novas tecnologias nos contextos educacionais, práticas pedagógicas inovadoras e o novo perfil docente.

$\mathrm{Na}$ documentação direta, foi elaborada um questionário/entrevista contendo 12 questões abertas, que foi aplicado aos coordenadores dos cursos superiores e aos diretores 
da IES, objeto do presente estudo. O período de aplicação foi no mês de novembro de 2021 de forma presencial. Ainda foram gerados dados acerca da consulta da documentação em formato de relatório de atividades realizadas pela IES, objeto desse estudo.

\section{ANÁLISE E INTERPRETAÇÃO DOS DADOS}

É necessário que os dados sejam coletados e organizados, para então serem analisados. Em vista disso, o método de abordagem utilizado na interpretação dos dados é o hipotético-dedutivo, pois se buscou atingir a solução para um problema. Também compreende o método comparativo, em relação aos dados com características qualitativas.

Após a aplicação dos questionários/entrevista, os dados foram tabulados e analisados, de maneira descritiva, sendo comparados com os conceitos do referencial teórico, estabelecendo uma relação entre os dados.

Na sequencia está a discussão e análise dos resultados.

\section{O NOVO PERFIL DOCENTE NO CONTEXTO DAS PRÁTICAS PEDAGÓGICAS INOVADORAS EM UMA IES DO NOROESTE GAÚCHO.}

Como principal agente de integração da mudança, o professor teve um papel fundamental na implementação das novas práticas pedagógicas de aprendizagem. Para o entrevistado $\mathrm{C}$ 1, a implementação das tecnologias ativas somente foi possível na IES pesquisada, porque os professores realmente acreditaram que este novo contexto de aprendizagem faria a diferença na formação dos acadêmicos.

Para o entrevistado D1, a nova realidade passou a exigir práticas pedagógicas que superassem as abordagens educacionais centradas na fala do professor, na leitura do livro e na passividade do estudante, que apenas responde às questões que lhe foram solicitadas. "Isso significa a abertura para a interconexão com a cultura digital”, afirmou.

Para ele, "metodologias ativas para uma educação inovadora, apontam a possibilidade de transformar aulas em experiências de aprendizagem mais vivas e significativas para os estudantes da cultura digital, cujas expectativas em relação ao 
ensino, à aprendizagem e ao próprio desenvolvimento e formação são diferentes do que expressavam as gerações anteriores".

Acreditar, engajar, cooperar, compartilhar experiências, demonstrar flexibilidade e querer a mudança, passam a fazer parte das atribuições do novo profissional de educação, conforme observado pelo entrevistado C5.

Neste sentido, estudantes atualmente inseridos nos sistemas de educação formal "requerem de seus professores habilidades, competências didáticas e metodológicas para as quais eles não foram preparados em sua formação", observa o entrevistado D1. Para ele, em função desse novo perfil de estudantes, o foco deve deixar de ser somente o conteúdo ou a aula expositiva, mas proporcionar experiências exitosas aos alunos por meio da prática e maior integração entre academia e organizações. “O professor deixa de ser simplesmente responsável por repassar conteúdos e assume a função de orientador da aprendizagem", destacou.

Baseado nos relatórios desenvolvidos pela instituição pesquisada e nas informações levantadas através da pesquisa aplicada, todos os entrevistados concordaram que o papel do professor diante do novo perfil docente no contexto das práticas pedagógicas inovadoras é fundamental e determinante.

Reinventar-se, buscando novas metodologias, observando os feedbacks recebidos, estimulando os acadêmicos e promovendo a troca de conhecimentos, passou a ser um exercício diário ao profissional docente, atuando como mediador e facilitador no processo de aprendizagem e tornando a educação mais democrática e humana, com participação mais ativa e o protagonismo do estudante como sujeito literalmente ativo na sua aprendizagem, conforme observam os entrevistados $\mathrm{C} 3$ e $\mathrm{C} 4$.

O entrevistado C2 acrescenta que nesse processo de intermediação, o docente vai planejar e desenvolver situações pedagógicas que irão desencadear o desenvolvimento de determinado objetivo que se pretende alcançar para aquela competência. "É planejamento do professor, considerando que ele é essa ponte que vai determinar a aprendizagem do aluno", destacou.

Sobre as metodologias ativas acompanhadas das TICs, o entrevistado C2 afirma que o diferencial não está nas plataformas ou tecnologias utilizadas, mas na posição que o professor ocupa perante o processo de ensino e aprendizagem. Afirma que o modelo tradicional não é um problema, “o problema é se o professor se sustentar somente naquilo 
que foi sua base e sua essência, ele precisa ressignificar, precisa evoluir conforme a própria concepção de sujeito aluno", observou.

Para o entrevistado $\mathrm{C} 2$, o protagonismo do aluno exige um professor protagonista. Este é o grande desafio, na visão do entrevistado D2, tendo em vista que o professor vem de uma formação acadêmica baseada no modelo tradicional de ensino, sendo necessário um grande esforço para sua adaptação às novas práticas exigidas pelo contexto atual.

\section{PRINCIPAIS CONTRIBUIÇÕES DA EAC - EXPERIÊNCIA DE APRENDIZAGEM COMBINADA, NO CONTEXTO DA IES PESQUISADA}

Através de atividades incorporadas ao novo modelo e um corpo docente totalmente integrado com as novas práticas pedagógicas, a vivência e experiência prática como aluno possibilitaram uma ressignificação da aprendizagem. Além de se preocupar com as competências técnicas, a EAC vem trabalhando fortemente no sentido de desenvolver nos alunos as competências ligadas a personalidade e ao comportamento profissional, ou seja, aptidões mentais, emocionais e sociais.

$\mathrm{O}$ entrevistado $\mathrm{C} 1$ acredita que a EAC trouxe inúmeras vantagens ao processo de aprendizagem, porém destaca a qualidade do profissional que está sendo entregue à sociedade, tendo em vista as habilidades e competências potencializadas pelo processo de ensino e aprendizagem aperfeiçoado. "O impacto foi extremamente positivo, pois potencializou o processo, deu apoio e ferramentas para que além das metodologias ativas analógicas, pudessem ser utilizadas e incorporadas ao dia a dia da academia as metodologias ativas digitais", explicou.

Para o entrevistado C2, além das vantagens percebidas no estudante, a implementação do novo modelo de aprendizagem devolveu aos professores a motivação e o prazer com a docência, através do orgulho e satisfação com os resultados e o êxito do aluno.

A necessidade de reinventar-se, fez com que cada professor tivesse de se reorganizar e repensar seu fazer docente, afirmou o entrevistado C3. Destacou ainda como principais vantagens na implementação da proposta de práticas pedagógicas inovadoras, a diversificação das atividades das aulas, a interdisciplinaridade, a autonomia e o protagonismo dos acadêmicos, resultando em melhoria na aprendizagem e alunos mais satisfeitos, conforme também avaliou o entrevistado D1. 
Outra vantagem apontada pelo entrevistado C2 é o desenvolvimento múltiplo de competências, como técnicas, comportamentais e emocionais, atuando de forma combinada na transformação do sujeito cidadão, conectando estudantes com a realidade através das vivências que estão sendo compartilhadas.

Segundo o entrevistado D2, este modelo de formação atual possibilita tanto para professores quanto para alunos, mais recursos e possibilidades de conexão e acesso à informação, com a socialização de eventos diários ocorridos em sala de aula ou fora dela.

Maior interação entre professores e alunos; busca por novas metodologias e trocas de ideias com os demais professores do grupo; alunos se apropriando do conhecimento; atividades de extensão; participação de empreendedores em sala de aula; aprendizado por meio de experiência prática; aumento de atividades interdisciplinares, foram as principais contribuições da EAC integrada com as metodologias ativas nos ambientes de aprendizagem no ensino superior, conforme avaliação do entrevistado C4.

Já para o entrevistado C5, a plataforma de aprendizagem foi um diferencial da FEMA no período da pandemia: "onde outras instituições apresentaram dificuldades de migração naquele momento, nós estávamos prontos e preparados para aquela mudança", destacou.

Desse modo, dentre tantos outros benefícios trazidos pela nova postura da FEMA, constatou-se que a referida instituição traça metas e constrói vias para se tornar referência, não só para o meio acadêmico e outras instituições de ensino, pois, estar em constante processo de aprendizado conduz para a consolidação da intencionalidade de ser uma instituição inovadora, segundo o entrevistado C5.

\section{INTERPRETAÇÃO DA REPRESENTAÇÃO GRÁFICA DOS DADOS COLETADOS JUNTO AOS COORDENADORES E DIRETORES DA FEMA}

Essencialmente, através do questionário aplicado aos Coordenadores e Diretores da FEMA e com base nos relatório de atividades desenvolvido pela própria instituição, a pesquisa busca elucidar os movimentos efetivos por parte da IES como um todo em relação às práticas pedagógicas inovadoras e suas implicações, razão deste estudo, bem como o posicionamento do seu corpo docente diante da formação continuada e o emprego das TICs aliadas às novas metodologias, como por exemplo, a EAC e o uso de PDAs - 
Plataformas Digitais de Aprendizagem, integradas com as metodologias ativas nos ambientes de aprendizagem no ensino superior.

Para a apuração destes dados, foram investigados os Coordenadores dos Cursos Superiores e Diretores da FEMA, tendo ainda como referencial o Relatório de Atividades 2020, desenvolvido pela IES pesquisada.

A ilustração a seguir demonstra, através de uma linha crescente que vai de 5 a 35 pontos, as áreas que sofreram maiores impactos, de acordo com a pesquisa de campo aplicada. Os pontos destacados no gráfico representam o número de vezes que cada sentença aparece nas repostas obtidas através do questionário aplicado aos entrevistados.

Ilustração 2 - Áreas impactadas mais mencionadas pelos entrevistados.

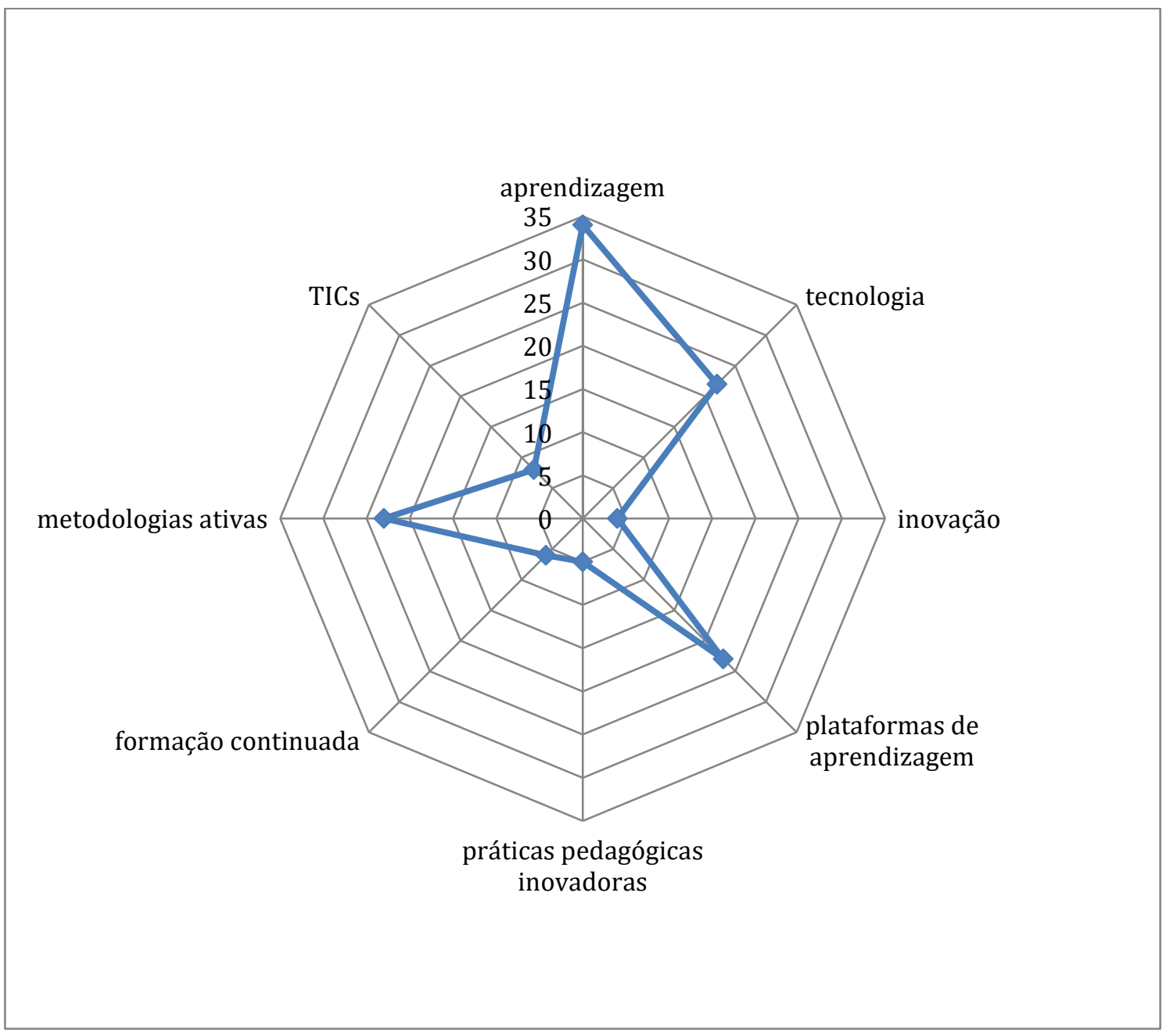

Fonte: Produção dos pesquisadores.

Com base nos dados levantados a partir das repostas obtidas junto aos entrevistados, é possível perceber a intensidade e profundidade das mudanças ocorridas 
durante o processo de implementação das novas práticas pedagógicas e ainda de que modo e forma as antigas metodologias tiveram sua convergência e aplicação como novas ferramentas para a continuidade dos trabalhos com os estudantes.

A necessidade de mudança de foco, do ensino para a aprendizagem, através de uma nova concepção de desenvolvimento de competências, mostra-se como o pontapé inicial de todo processo de evolução na metodologia de ensino adotada pela instituição, objeto deste estudo. Não é por acaso que a palavra 'aprendizagem' aparece disparadamente em maior número de citações em todas as abordagens dos entrevistados. Paralelo a isto, o termo 'plataformas de aprendizagem' também apresenta destaque nos documentos analisados.

Observa-se ainda que o novo modelo de aprendizagem requer, além de uma mudança pedagógica, também uma mudança estrutural. Neste sentido, a partir dos relatos dos entrevistados, pode-se perceber um grande movimento institucional a fim de instrumentalizar o educandário para o novo cenário educativo.

A partir da vontade dos gestores e do comprometimento dos professores, teve início não exatamente uma mudança, mas uma evolução do modelo de aprendizagem, pois muito do chamado modelo tradicional permaneceu, sendo melhorado através da implementação de metodologias ativas, que potencializaram o processo de aprendizagem. Para além disso, a possibilidade de tecnologia estar presente e a implementação das TICs e plataformas de aprendizagem, surgiram como facilitadoras no desenvolvimento e formação das competências acadêmicas.

De acordo com os entrevistados, a metodologia tradicional serviu como alicerce para a implementação das metodologias ativas, que acompanhadas das TICs, entre elas as próprias PDAs, tornaram-se instrumentos deste processo de transmissão do conhecimento. No contexto da FEMA, a utilização da plataforma de aprendizagem acelerou a implantação de metodologias ativas, através de ferramentas que auxiliam alunos e professores no processo de utilização destes recursos.

A necessidade de evolução das práticas pedagógicas existentes, seja pelo novo perfil do estudante ou ainda pelas crescentes exigências do cenário profissional, desencadeou o surgimento das chamadas práticas pedagógicas inovadoras, através de metodologias vivas, ativas, inovativas e imersivas. Para tanto, as TICs tornaram-se importante suporte para a implementação destes recursos pedagógicos, potencializando o 
processo por meio de ferramentas incorporadas ao dia a dia da academia, ampliando os espaços de aprendizado e gerando novas possibilidades na busca pelo conhecimento.

Metodologias ativas para uma educação inovadora, apontam a possibilidade de transformar aulas em experiências de aprendizagem mais vivas e significativas para os estudantes da cultura digital, cujas expectativas em relação ao ensino, à aprendizagem, ao saber e ao próprio desenvolvimento e formação são diferentes do que expressavam as gerações anteriores. Neste sentido, os termos 'tecnologia' e 'metodologias ativas', também aparecem entre as mais frequentes citações dos entrevistados, conforme aponta o gráfico. Aliado a isso, a palavra 'TICs' também é unânime entre as respostas obtidas através dos questionários aplicados na pesquisa.

No entanto, apesar da metodologia ativa estar, na maioria das vezes, interrelacionada às tecnologias, a intencionalidade do professor é que define os recursos que serão utilizados no processo pedagógico. Os estudantes que estão, hoje, inseridos nos sistemas de educação formal requerem de seus professores habilidades, competências didáticas e metodológicas para as quais eles não foram preparados em sua formação. Neste sentido, a formação continuada mostrou-se como elemento fundamental e decisivo para o êxito deste processo.

Para tanto, a FEMA instituiu uma extensão para a formação interna de professores, nomeada Práticas Pedagógicas Inovadoras, promovendo uma transição de tecnologias educacionais que vieram a permear as mudanças no ensino para formação das competências acadêmicas. Assim, a implementação destas práticas inovadoras, levaram em conta a necessidade de promover o processo de transformação humano do próprio professor, a fim de instrumentalizá-lo para que pudesse instrumentalizar os outros. Diante disto, os termos 'formação continuada', 'práticas pedagógicas inovadoras' e 'inovação', completam o conjunto de palavras destacadas no gráfico a seguir.

Deste modo, verifica-se que não seria possível a implementação de novas práticas pedagógicas, sem inovação, investimento estrutural e humano, tecnologia e um planejamento estratégico que culminasse na sinergia e engajamento de todos os profissionais e estudantes envolvidos neste processo, levando a IES pesquisada a um novo patamar no cenário educativo regional, tornando-se referência na implantação destas metodologias.

CONSIDERAÇÕES FINAIS 
A análise das experiências apresentadas e discutidas neste estudo oportunizou refletir sobre novas práticas de ensino e compreender como a inovação dos processos educativos contribuiu como elemento fundamental para o processo evolutivo de aprendizagem na IES objeto deste estudo. Do ponto de vista institucional, a decisão de superar o modelo tradicional de ensino e aprendizagem, levou os professores a repensar suas práticas educativas, migrando de uma abordagem centralizada na transmissão de conteúdos fechados, que pouco dialogam com o dia a dia dos estudantes, para alternativas pedagógicas que transcendem os espaços escolares e refletem nas dimensões do desenvolvimento humano, levando o estudante a assumir o papel de protagonista no processo de ensino-aprendizagem.

Este movimento que contrapõe a lógica tradicional de ensino unilateral para uma aprendizagem mais dinâmica e ativa, permitiu compreender a importância e as implicações da inserção e desenvolvimento destas práticas no processo de formação acadêmica, gerando impactos que possivelmente serão um diferencial no exercício da cidadania. Neste sentido, evidenciou-se que as metodologias pedagógicas e sua relação com as práticas inovadoras de ensino constituem instrumentos fundamentais que refletem nos processos formativos, uma vez que demonstram esse potencial de inovação e transformação do cidadão no mundo e com o mundo.

A tecnologia como elemento inovador destas experiências, mostrou-se extremamente relevante no planejamento, organização e desenvolvimento destas propostas e estratégias pedagógicas, oferecendo singular contribuição à construção do processo de aprendizagem.

A intensa expansão do uso social das tecnologias digitais de informação e comunicação, sob forma de diversos dispositivos móveis conectados à internet sem fio, utilizados em diferentes espaços, tempos e contextos, observada na segunda década do século XXI, gerou e continua gerando mudanças sociais que provocam a dissolução de fronteiras entre espaço virtual e físico, criando um ambiente hibrido de conexões que propiciam infinitas experiências de aprendizagem, que podemos denominar de EAC Experiência de Aprendizagem Combinada, também conhecida popularmente como Ensino Híbrido (MATTAR, 2017).

Portanto, na convergência entre espaços presenciais e virtuais, surgem novos modos de expressar pensamentos, sentimentos, crenças e desejos, por meio de uma diversidade de tecnologias e linguagens midiáticas empregadas para interagir, criar, 
estabelecer relações e aprender. Essas mudanças convocam participação, colaboração, requerem uma posição crítica em relação à tecnologia, à Informação e ao conhecimento, influenciam a cultura levando à emergência da cultura digital (BACICH; MORAN, 2018).

Percebe-se ainda que tal contexto somente se concretiza, a partir de um conjunto de esforços que envolvem, além de uma reorganização estrutural, uma ressignificação dos processos de ensino e aprendizagem, cujo desvelar-se em novas perspectivas de prática pedagógica lhe seja inerente.

Face ao exposto, conclui-se que a relação entre metodologias pedagógicas e inovação educativa oferecem um diferencial capaz de instrumentalizar os estudantes, por meio do conhecimento adquirido através de abordagens que se relacionam com a forma de vida e interação entre os próprios sujeitos, garantindo-lhes a capacidade de compreender e transformar suas condições de existência.

\section{REFERÊNCIAS}

BACICH, Lilian; MORÁN, José. Metodologias ativas para uma educação inovadora: uma abordagem teórico-prática. Porto Alegre: Penso, 2018.

CAMARGO, Fausto. A sala de aula inovadora: estratégias pedagógicas para fomentar o aprendizado ativo. Porto Alegre: Penso, 1 ed., 2018.

CAVILHEIRI, Alceu; ENGERROFF, Sérgio N.; SILVA, Jolair da Costa. As Novas

Tecnologias e os Desafios para uma Educação Humanizadora. Santa Maria: Biblos, 2013. Data publicação: 27/06/2018, acessado em 25/08/2021.

DEMO, P. Alfabetizações: desafios para uma nova mídia. Disponível em: <http://www.scielo.br/scielo.php?pid=S0104-40362007000400006\&script=sci_arttext $>$. Acesso em: 26/10/2021.

FAGUNDES, Magali dos Reis. A Creche no Trabalho...O Trabalho na Creche. Um estudo sobre o Centro de Convivência Infantil da Unicamp: Trajetória e Perspectivas. Campinas, Unicamp, 1997.

FAVA, Rui. Trabalho, Educação e Inteligência Artificial: A Era do Indivíduo Versátil. Porto Alegre: Penso, 1 ed., 2018.

FAVA, Rui. Uma conversa com Rui Fava sobre educação, trabalho e tecnologia. Disponível em: https://desafiosdaeducacao.com.br/rui-fava-educacao-trabalho-tecnologia. Acessado em: $30 / 10 / 2021$.

FAZENDA, Ilario. C. A (Org.). O que é interdisciplinaridade? São Paulo: Cortez, 2008. 
FREIRE, Paulo. Pedagogia da Autonomia: saberes necessários a prática educativa. 9 ed. São Paulo: Paz e Terra, 1997.

GIL, Antônio Carlos. Como elaborar projetos de pesquisa. 5.ed.São Paulo: Atlas, 2010.

LAKATOS, Eva Maria; MARCONI, Marina de Andrade. Fundamentos de metodologia científica. 7.ed. São Paulo: Atlas. 2010.

LUCENA, Marisa. Um Modelo de Escola Aberta na Internet Kidlink no Brasil. Rio de Janeiro: Brasport, 1997.

LUCKIN, R., Holmes, W., Griffiths, M. \& Forcier, L. B. Intelligence Unleashed. An argument for AI in Education. London: Pearson. 2016.

MATTAR, João. Games em educação: como os nativos digitais aprendem. São Paulo: Pearson Prentice Hall, 2010.

MATTAR, João. Metodologias ativas para a educação presencial, blended e a distância. São Paulo: Artesanato Educacional, 2017.

MORAN, José. Mudando a educação com metodologias ativas. In: Coleção Mídias Contemporâneas. Convergências Midiáticas, Educação e Cidadania: aproximações jovens. Vol. II, Carlos Alberto de Souza e Ofélia Elisa Torres Morales (orgs.). Ponta Grossa:

UEPG/PROEX, 2015.

NEVES, Valdemar José das; MERCANTI, Luiz Bitencourt; LIMA, Maria Tereza.

Metodologias ativas: perspectivas teóricas e práticas no ensino superior. Campinas, São Paulo: Pontes Editores, 2018.

PEIXOTO, Anderson Gomes. O uso de Metodologias Ativas como Ferramenta de Potencialização da Aprendizagem de Diagramas de Caso de Uso. Periódico Científico Outras Palavras, volume 12, número 2, ano 2016.

VASCONCELLOS, Celso. Souza. Formação didática do educador contemporâneo: desafios e perspectivas. In: Universidade Estadual Paulista. Prograd. Caderno de Formação: formação de professores didática geral. São Paulo: Cultura Acadêmica, v. 9, p. 33-58, 2011.

WARSCHAUER, M. Tecnologia e inclusão social: a exclusão digital em debate. Tradução Carlos Szlak. São Paulo: Editora Senac São Paulo, 2006.

ZABALA, André. A prática educativa: como ensinar. Tradução: Ernani F. Da Rosa. Porto Alegre: Artmed, 1998. 